\title{
PERANCANGAN MODUL MENGGAMBAR TEKNIK BERBASISKAN KOMPETENSI UNTUK PROGRAM STUDI TEKNIK INDUSTRI FAKULTAS TEKNIK IBNU SINA
}

\author{
Albertus Laurensius Setyabudhi*1, Sanusi ${ }^{2}$ \\ ${ }^{1,2}$ Universitas Ibnu Sina; Jl. Teuku Umar, Lubuk Baja \\ 1,2Program Studi Teknik Industri, Universitas Ibnu Sina, Batam \\ e-mail: $\underline{* 1 \text { abyan@uis.ac.id, }}$ ${ }^{2}$ sanusi@ uis.ac.id
}

\begin{abstract}
Abstrak
Penelitian ini bertujuan untuk: (1) mengembangkan modul pembelajaran menggambar teknik program studi teknik industri fakultas teknik universitas ibnu sina. (2) mengetahui hasil dan tingkat kelayakan yang diperoleh dari pengujian validasi modul sebagai sumber belajar menggambar teknik oleh ahli media, ahli materi, dan guru mata pelajaran. Metode yang digunakan dalam penelitian adalah Research and Development (R\&D) yang mengacu model penelitian dan pengembangan 4D terdiri empat tahap utama, yaitu define, design, develop, dan disseminate. Subjek penelitian ini adalah ahli materi, ahli media dan dosen menggambar teknik program studi teknik industri fakultas teknik ibnu sina. Penelitian dilaksanakan pada Februari sampai Juni 2019. Metode pengumpulan data yang digunakan adalah observasi dan kuisioner. Teknik analisis data dalam penelitian ini adalah deskriptif yang menggunakan skala likert dalam 4 kategori kelayakan. Hasil dari penelitian ini berupa Modul Mata kuliah menggambar teknik program studi teknik industri. Tahap define terdapat lima kegiatan yaitu front and analysis, learner analysis, task analysis, concept dan specifiying intructional objectives. Tahap design terbagi empat kegiatan yaitu constructing criterion reforenced test, media selection, format selection dan initial design. Tahap develop, terdapat 3 kegiatan, analisis kebutuhan modul, validasi produk dan revisi modul. Tahap disseminate terdapat dua kegiatan yaitu packaging dan diffusion and adoption. Hasil kelayakan modul dari ahli materi mendapatkan persentase $85 \%$ dengan kategori "sangat layak". Ahli media mendapatkan persentase 96,87\% dengan kategori "sangat layak". Dosen Mata Kuliah mendapatkan persentase 85\% dengan kategori "sangat layak".
\end{abstract}

Kata kunci- media pembelajaran, modul, menggambar teknik

\begin{abstract}
This research aims to: (1) develop a drawing learning module for engineering study program of industrial engineering program at the Faculty of Engineering, Ibn Sina University. (2) know the results and the level of feasibility obtained from testing the module validation as a learning resource drawing technique by media experts, material experts, and subject teachers. The method used in research is Research and Development $(R \& D)$ which refers to the $4 D$ research and development model consisting of four main stages, namely define, design, develop, and disseminate. The subjects of this study were material experts, media experts and lecturers drawing techniques in the industrial engineering study program of the Faculty of Engineering Ibnu Sina. The study was conducted in February to June 2019. Data collection methods used were observation and questionnaires. The data analysis technique in this study was descriptive using a Likert scale in 4 feasibility categories. The results of this study are in the form of a Course Module drawing techniques in industrial engineering study programs. The define phase consists of five activities namely front and analysis, learner analysis, task analysis, concept and specific instructional objectives. The design phase is divided into four activities, namely constructing criterion refined tests, media selection, format selection and initial design. The develop phase,
\end{abstract}


there are 3 activities, module needs analysis, product validation and module revisions. Disseminate phase there are two activities namely packaging and diffusion and adoption. The module eligibility results from material experts get a percentage of $85 \%$ with the category "very feasible". Media experts get a percentage of $96.87 \%$ with the category "very feasible". Course lecturers get a percentage of $85 \%$ with the category "very decent".

Keywords—media learning, modules, drawing

\section{PENDAHULUAN}

Salah satu syarat untuk memasuki persaingan global adalah dengan melahirkan lulusan perguruan tinggi yang berkualitas, hingga nantinya dapat bersaing secara global. Dengan terbatasnya lapangan pekerjaan bagi lulusan perguruan tinggi, maka para lulusan tersebut dituntut dapat menciptakan lapangan kerja sendiri, yang akan menjadi faktor utama dalam menghadapi persaingan global. Untuk menciptakan peluang kerja sendiri tentunya peserta didik harus memunyai keahlian dan kompetensi yang tinggi.

Proses pembelajaran pada jenjang pendidikan tinggi mengarahkan mahasiswa untuk memiliki keahlian dan keterampilan serta mempunyai bekal ilmu berwirausaha. Adapun mata kuliah yang mendukung kompetensi kearah tersebut pada Program Studi Teknik Industri salah satunya adalah Menggambar Teknik. Sistem pembelajaran yang berlangsung selama ini belum mengantarkan mahasiswa untuk siap dan terampil dalam memasuki persaingan di dunia kerja.

Berdasarkan hasil pre-test mahasiswa pada mata kuliah menggambar teknik program studi Teknik Industri belum mencapai batas kriteria ketuntasan yang dipersyaratkan yaitu diatas 59.99 (C). Pada kelas 2A dengan jumlah mahasiswa 40 orang, pada kelas 2A sebanyak 28 mahasiswa yang tidak tuntas dengan persentase $70 \%$ dan 12 mahasiswa yang mendapatkan nilai tuntas dengan persentase $30 \%$. Sedangkan pada kelas 2B dengan jumlah mahasiswa 40 orang, 30 mahasiswa yang tidak tuntas dengan persentase $75 \%$ dan 10 mahasiswa mendapatkan nilai tuntas dengan persentase $25 \%$.

Dari hasil pengalaman mengajar menggambar teknik di program studi teknik industri fakultas teknik ibnu sina, penyampaian materi pada mata kuliah menggambar teknik oleh dosen kebanyakan hanya menggunakan metode demonstrasi tradisional tanpa memanfaatkan dan mengoptimalkan media pembelajaran yang ada. Metode ini menjadi efektif apabila didukung dengan media yang bervariasi. Penggunaan media dapat membantu mahasiswa lebih memahami materi dan dapat mengulang isi materi ketika diperlukan. Media pembelajaran dapat diakses dan dimiliki oleh mahasiswa melalui perantara buku, komputer atau yang lainnya. Metode demonstrasi tradisional yang digunakan tidak selamanya dapat diulang secara terus menerus ketika mahasiswa belum memahami materi yang telah disampaikan. Dosen sebagai pendemonstran akan mengalami keletihan dan kejenuhan ketika harus mengulang secara terus menerus materi yang telah disampaikan kepada mahasiswa. Ketika hal ini terjadi mahasiswa menjadi bosan dan merasa kurang tertarik terhadap materi yang disampaikan, sehingga suasana kelas dirasa sangat membosankan. Selain itu, tanpa didukung media mahasiswa hanya dijadikan objek dan dosen menjadi satu-satunya sumber informasi bagi mahasiswa sehingga proses pembelajaran berjalan satu arah dan tidak ada interaksi antar dosen dan mahasiswa.

Untuk menghindari hal tersebut, diperlukan media pembelajaran yang dapat menunjang keberlangsungan proses pembelajaran sehingga dapat mempermudah dosen 
ketika menyampaikan materi dan mahasiswa tidak merasa monoton dan membosankan. Media digunakan sebagai alat bantu proses pembelajaran sehingga proses belajar mengajar lebih efisien. Penggunaan media dengan pemanfaatan sarana pembelajaran yang berisi materi, metode, batasan-batasan materi pembelajaran, petunjuk kegiatan belajar, dan latihan.

Menurut Hamalik (1986: 145) modul adalah suatu paket pengajaran yang berisi suatu unit terkecil dan bertahap dari suatu mata pelajaran tertentu. Modul disusun agar mahasiswa dapat menguasai kompetensi yang diajarkan dalam diklat atau kegiatan pembelajaran dengan sebaik-baiknya. Bagi dosen, modul bisa digunakan sebagai acuan dalam menyajikan dan memberikan materi selama diklat atau kegiatan pembelajaran berlangsung. Menurut Hartoyo (2009: 64), modul adalah bahan ajar yang disusun secara sistematis dan menarik yang mencakup isi materi, metoda, dan evaluasi yang dapat digunakan secara mandiri.

Berdasarkan pendapat-pendapat tersebut, dapat disimpulkan bahwa modul adalah media pembelajaran yang mendorong mahasiswa untuk belajar secara mandiri serta membantu dosen dalam menyampaikan materi agar tercapainya tujuan pembelajaran.

\section{METODE PENELITIAN}

Menghasilkan produk tertentu digunakan penelitian yang bersifat analisis kebutuhan dan menguji keefektifan produk tersebut supaya dapat berfungsi di masyarakat luas, maka diperlukan penelitian untuk menguji keefektifan produk (metode mind mapping). Metode penelitian yang digunakan dalam penelitian adalah metode penelitian dan pengembangan atau Research and Development (R\&D). Menurut Sugiyono (2012:297) R\&D dapat diartikan sebagai penelitian yang digunakan untuk menghasilkan produk tertentu.

Penelitian ini mengacu pada model penelitian dan pengembangan 4D. Menurut Thiagarajan (1974) model penelitian dan pengembangan 4D terdiri atas empat tahap utama, yaitu define, design, develop, dan disseminate.

Subjek pada penelitian ini adalah ahli materi, ahli media, dan dosen mata kuliah. Subjek yang digunakan dalam penelitian ini adalah 1 dosen ahli materi dan 1 dosen ahli media dari Teknik Industri dan 1 dosen Mata kuliah menggambar Teknik Program studi teknik industri fakultas teknik universitas ibnu sina.

Penelitian pengembangan modul menggambar teknik dilakukan di program studi teknik industri fakultas teknik ibnu sina. Penelitian dilaksanakan pada bulan Februari sampai Juni 2019.

Teknik pengumpulan data pada penelitian pengembangan ini dengan menggunakan observasi dan penyebaran kuesioner. Sedangkan untuk alat pengumpul data yang digunakan dalam penelitian ini adalah kuesioner, wawancara, dan observasi.

Validitas dilakukan untuk mengetahui layak tidaknya suatu kuesioner. Kuesioner dapat dikatakan valid apabila dapat mengukur sesuatu sesuai dengan yang diharapkan Validasi dilakukan dengan menunjukan alat pengumpulan data kepada dua orang dosen ahli dan dosen.

Metode analisis yang digunakan dalam penelitian kuantitatif merupakan metode analisis deskriptif. Analisis deskriptif yaitu penggambaran atau pendeskripsian secara sistematis, faktual, dan akurat terhadap masalah yang diselidiki. Instrumen akan digunakan dalam penelitian kuantitatif untuk mengumpulkan data, instrumen digunakan untuk mengukur nilai variabel yang 
akan diteliti. Setiap instrument harus mempunyai skala agar dihasilkan data yang akurat.

\section{HASIL DAN PEMBAHASAN}

\section{A. Hasil}

Penyajian data dalam penelitian ini terdapat 3 macam, yaitu data hasil validasi oleh dosen ahli media, dosen ahli materi, dan dosen mata kuliah di program studi teknik industri fakultas teknik universitas ibnu sina. Data penelitian diperoleh dari lembar penelitian berupa angket penilaian yang diberikan oleh peneliti kepada validator.

Tabel 1. Persebaran Hasil Validasi Ahli Materi

\begin{tabular}{|l|l|l|l|l|l|l|}
\hline \multirow{2}{*}{ No } & \multirow{2}{*}{ Aspek } & \multirow{2}{*}{ Bumlah } & \multicolumn{4}{|l|}{ Persebaran Skor } \\
\cline { 3 - 7 } & & 1 & 2 & 3 & 4 \\
\hline 1 & Self instruction & 15 & 0 & 0 & 9 & 6 \\
\hline 2 & Self contained & 4 & 0 & 0 & 1 & 3 \\
\hline 3 & Stad alone & 1 & 0 & 0 & 1 & 0 \\
\hline 4 & Adaptive & 4 & 0 & 0 & 4 & 0 \\
\hline 5 & User Friendly & 6 & 0 & 0 & 3 & 3 \\
\hline Jumlah & 30 & 0 & 0 & 18 & 12 \\
\hline
\end{tabular}

Tabel 2. Analisis Data Penilaian Validasi Ahli Materi

\begin{tabular}{|l|l|l|l|l|l|l|}
\hline No & Aspek & $\begin{array}{l}\text { Jumlah } \\
\text { Butir }\end{array}$ & Skor $(\mathbf{x})$ & $\begin{array}{l}\text { Skor } \\
\text { maksimum }\end{array}$ & $\begin{array}{l}\text { Rata- } \\
\text { rata }\end{array}$ & $\begin{array}{l}\text { Persentase } \\
(\%)\end{array}$ \\
\hline 1 & Self instruction & 15 & 51 & 60 & 3,40 & $85 \%$ \\
\hline 2 & Self contained & 4 & 15 & 16 & 3,75 & $93,75 \%$ \\
\hline 3 & Stad alone & 1 & 3 & 4 & 3,00 & $75 \%$ \\
\hline 4 & Adaptive & 4 & 12 & 16 & 3,00 & $75 \%$ \\
\hline 5 & User Friendly & 6 & 21 & 24 & 3,50 & $87,50 \%$ \\
\hline Jumlah & 30 & 102 & 120 & 3,40 & $85 \%$ \\
\hline
\end{tabular}

Berdasarkan kriteria penilaian materi secara keseluruhan dengan skor 102 termasuk dalam kategori "Sangat Layak". Sedangkan data penlilaian hasil validasi dosen ahli media dapat dilihat pada tabel dibawah ini:

Tabel 3. Persebaran Hasil Validasi Ahli Media

\begin{tabular}{|l|l|l|l|l|l|l|}
\hline \multirow{2}{*}{ No } & \multirow{2}{*}{ Aspek } & Jumlah & \multicolumn{4}{l|}{ Persebaran Skor } \\
\cline { 3 - 7 } & & Butir & 1 & 2 & 3 & 4 \\
\hline 1 & Ukuran Buku & 2 & 0 & 0 & 1 & 1 \\
\hline 2 & $\begin{array}{l}\text { Desain Cover } \\
\text { Buku }\end{array}$ & 16 & 0 & 0 & 3 & 13 \\
\hline 3 & Desain Buku & 30 & 0 & 0 & 2 & 28 \\
\hline Jumlah & 48 & 0 & 0 & 6 & 42 \\
\hline
\end{tabular}

Tabel 4. Analisis Data Penilaian Validasi Ahli Media

\begin{tabular}{|l|l|l|l|l|l|l|}
\hline No & Aspek & $\begin{array}{l}\text { Jumlah } \\
\text { Butir }\end{array}$ & Skor $(\mathbf{x})$ & $\begin{array}{l}\text { Skor } \\
\text { maksimum }\end{array}$ & $\begin{array}{l}\text { Rata- } \\
\text { rata }\end{array}$ & $\begin{array}{l}\text { Persentase } \\
(\boldsymbol{\%})\end{array}$ \\
\hline 1 & Ukuran Buku & 2 & 7 & 8 & 3,50 & $87,50 \%$ \\
\hline 2 & Desain Cover Buku & 16 & 61 & 64 & 3,81 & $95,31 \%$ \\
\hline 3 & Desain Buku & 30 & 118 & 120 & 3,93 & $98,33 \%$ \\
\hline Jumlah & 48 & 186 & 192 & 3,87 & $96,87 \%$ \\
\hline
\end{tabular}


Berdasarkan kriteria penilaian materi secara keseluruhan dengan persentase 96,87\% termasuk dalam kategori "Sangat Layak". Untuk data penlilaian hasil validasi dosen mata kuliah menggambar teknik dapat dilihat pada tabel dibawah ini:

Tabel 5. Persebaran Hasil Validasi Materi oleh Dosen Mata Kuliah

\begin{tabular}{|c|c|c|c|c|c|c|}
\hline \multirow{2}{*}{ No } & \multirow{2}{*}{ Aspek } & \multirow{2}{*}{$\begin{array}{l}\text { Jumlah } \\
\text { Butir }\end{array}$} & \multicolumn{4}{|c|}{ Persebaran Skor } \\
\hline & & & 1 & 2 & 3 & 4 \\
\hline 1 & Self instruction & 15 & 0 & 0 & 8 & 7 \\
\hline 2 & Self contained & 4 & 0 & 0 & 1 & 3 \\
\hline 3 & Stad alone & 1 & 0 & 0 & 1 & 0 \\
\hline 4 & Adaptive & 4 & 0 & 0 & 4 & 0 \\
\hline 5 & User Friendly & 6 & 0 & 0 & 4 & 2 \\
\hline \multicolumn{2}{|c|}{ Jumlah } & 30 & 0 & 0 & 18 & 12 \\
\hline
\end{tabular}

Tabel 6. Analisis Data Penilaian Validasi Materi oleh Dosen Mata Kuliah

\begin{tabular}{|l|l|l|l|l|l|l|}
\hline No & Aspek & $\begin{array}{l}\text { Jumlah } \\
\text { Butir }\end{array}$ & Skor $(\mathbf{x})$ & $\begin{array}{l}\text { Skor } \\
\text { maksimum }\end{array}$ & $\begin{array}{l}\text { Rata- } \\
\text { rata }\end{array}$ & $\begin{array}{l}\text { Persentase } \\
(\%)\end{array}$ \\
\hline 1 & Self instruction & 15 & 52 & 60 & 3,46 & $87 \%$ \\
\hline 2 & Self contained & 4 & 15 & 16 & 3,75 & $93,75 \%$ \\
\hline 3 & Stad alone & 1 & 3 & 4 & 3,00 & $75 \%$ \\
\hline 4 & Adaptive & 4 & 12 & 16 & 3,00 & $75 \%$ \\
\hline 5 & User Friendly & 6 & 20 & 24 & 3,33 & $83 \%$ \\
\hline Jumlah & 30 & 102 & 120 & 3,40 & $85 \%$ \\
\hline
\end{tabular}

Berdasarkan kriteria penilaian materi secara keseluruhan dengan skor 102 termasuk dalam kategori "Sangat Layak".

\section{B. Pembahasan}

Model pengembangan yang digunakan dalam penelitian ini adalah pengembangan dengan model 4D Thiagarajan yang meliputi define (pendefinisian), design (perancangan), develop (pengembangan), dan disseminate (penyebarluasan). Kelayakan media pembelajaran didapatkan dari penilaian kelayakan yang dilakukan oleh dosen ahli media, dosen ahli materi dan dosen mata kuliah sebagai ahli materi. Sehingga apabila dikembangkan sesuai dengan prosedur pengembangan, maka akan menghasilkan produk yang bermutu dan layak digunakan sebagai sumber belajar.

Pengujian kelayakan modul oleh dosen ahli media, dosen ahli materi, dan dosen mata kuliah menghasilkan beberapa masukan dan revisi. Masukan dan revisi ini kemudian digunakan untuk menyempurnakan media pembelajaran agar lebih interaktif, mendetail, dan mudah dipahami oleh mahasiswa.

Hasil validasi dosen ahli materi mendapatkan skor 102 berada pada interval skor kelayakan 97,5 $<\mathrm{x} \leq 120$ termasuk kategori sangat layak, sedangkan persentase dengan skor $85,00 \%$ termasuk dalam kategori sangat layak. Hasil validasi ahli media mendapatkan skor 186 berada pada interval skor kelayaka $156<\mathrm{x} \leq 192$ termasuk kategori sangat layak, sedangkan persentase dengan skor $96,87 \%$ termasuk dalam kategori sangat layak. Hasil validasi oleh guru Mata Kuliah Menggambar Teknik mendapatkan skor 102 berada pada interval skor kelayakan $97,5<\mathrm{x} \leq 120$ termasuk kategori sangat layak, sedangkan persentase dengan skor 85,00\% termasuk dalam kategori sangat layak. Dari hasil analisis data validasi dosen ahli media, dosen ahli materi, dan dosen mata kuliah program studi teknik industri fakultas teknik universitas ibnu sina, media yang dikembangkan termasuk dalam kategori layak sehingga modul tersebut dapat digunakan untuk proses pembelajaran mahasiswa program studi teknik industri yang mempelajari menggambar teknik di Fakultas Teknik Universitas Ibnu Sina. 


\section{SIMPULAN}

Berdasarkan hasil penelitian dan pengembangan media pembelajaran Modul Mata Kuliah Menggambar Teknik Program Teknik Industri Fakultas Teknik Universitas Ibnu Sina, maka peneliti dapat mengambil kesimpulan sebagai berikut: (1). Hasil dari penelitian ini berupa Modul Mata Kuliah Menggambar Teknik Program Teknik Industri Fakultas Teknik Universitas Ibnu Sina. Pengembangan produk menggunakan metode 4D oleh Thiagarajan yaitu melalui tahap define, design, develop, dan disseminate, (2) Kelayakan modul pembelajaran Teknik Pengukuran Tanah dilakukan dengan penilaian oleh dosen ahli materi, dosen ahli media dan guru mata pelajaran.

\section{SARAN}

Berdasarkan hasil penelitian dan kesimpulan yang sudah disampaikan, maka saran yang dapat diberikan oleh peneliti untuk penelitian selanjutnya adalah sebagai berikut: (1) Penambahan variasi soal pada media pembelajaran., (2) Pengembangan media pembelajaran dengan lebih lengkap, menarik serta interaktif baik untuk komponen materi maupun tampilan modul, (3) Perlu dilakukan uji keefektifan penggunaan modul Mata Kuliah Menggambar Teknik Program Teknik Industri Fakultas Teknik Universitas Ibnu Sina sehingga bisa diketahui bagian modul yang sulit dipelajari dan harus diperbaiki serta untuk mengetahui seberapa besar efektifitas modul bagi proses pembelajaran di dalam kelas., (4) Modul yang telah selesai dikembangkan sebaiknya diajukan untuk memperoleh hak cipta.

\section{UCAPAN TERIMA KASIH}

Penulis mengucapkan terima kasih kepada DRPM Direktorat Jendral penguat Riset dan Pengembangan ristekdikti atas bantuan pendanaan yang diberikan. Penelitian penulis didanai oleh Hibah Penelitian Dosen Pemula DRPM Dikti tahun 2018. Selanjutnya terima kasih kepada LPPM Universitas Ibnu Sina yang membantu dan mendukung proses dalam penelitian ini.

\section{DAFTAR PUSTAKA}

Abdullah, R. (2012). Pembelajaran Berbasis Pemanfaatan Sumber Belajar. Jurnal Didaktika, 2 (12) : 216-231.

Anwar, I. (2010). Pengembangan Bahan Ajar. Bahan Kuliah Online. Direktori UPI. Bandung.

Awaliyah, F. (2013). Peran Guru Dalam Kurikulum 2013. Jurnal Aspirasi, 4 (1) : $65-74$.

Burke, J. W. (1989). Competency based education and training. Psychology Press.

Costa, A. (2002). Changing curriculum means changing your mind. Tenth International Conference on Thinking, Harrogate, England.

Doppelt, Y. (2003). Implementation and assessment of project-based learning in a flexible environment. International Journal of Technology and Design Education, 13(3), $255-272$. 
Daryanto. (2013). Menyusun Modul (Bahan Ajar untuk Persiapan Guru dalam mengajar). Yogyakarta: PT. Gava Media.

Hamalik, O. (1986). Media Pendidikan. Bandung: PT Alumni.

Hartoyo. (2009). Upaya Meningkatkan Presentasi Melalui Pembelajaran dengan

Modul Berbasis Kompetensi. Jurnal Pendidikan Teknologi dan Kejuruan, 18 (1) : 61-83. Hujair, A.H.S. (2013). Media Pembelajaran Interaktif-Inovatif. Yogyakarta: Kaukaba Dipantara.

Muhammad, A. (2014). Perbandingan Strategi Pembelajaran Teacher Centered Learning dengan Student Centered Learning terhadap Hasil Belajar Siswa Kelas VIII SMP Muhammadiyah 4 Surakarta. TAS UMS.

Mustholiq, I., Sukir., dan Chandra, A. (2007). Pengembangan Media Pembelajaran Interaktif Berbasis Multimedia pada Mata Kuliah Dasar Listrik. Jurnal Pendidikan Teknologi dan Kejuruan, 16 (1) : 1-18.

Nasution, S. (2008). Berbagai Pendekatan dalam Proses Belajar \& Mengajar.Jakarta: PT. Bumi Aksara.

Permana, Y. (2017). Pengembangan Modul Pembelajaran Autocad dengan Konsep

Purnawan, Y. (2007). Pengenalan PBL (Pembelajaran Berbasis Proyek).

Spencer, L. M., \& Spencer, P. S. M. (2008). Competence at Work models for superior performance. John Wiley \& Sons.

Stufflebeam, D. L. (2007). CIPP evaluation model checklist. Retrieved January, 8, 2012.

Wheelen, T. L., Hunger, J. D., Hoffman, A. N., \& Bamford, C. E. (2010). Strategic management and business policy. Prentice Hall New Jersey.

Winkel, W. S. (2006). Psikologi Pengajaran (Cetakan ke-15). Jakarta: Grasindo.

Yunita, N., \& Susilowati, E. (2010). Makalah Pengembangan Modul. Universitas Sebelas Maret: Lembaga Penelitian Dan Pengabdian Masyarakat 